\title{
Experimental Investigation of Single-Phase Heat Transfer on Scalable Nanostructured Microchannels
}

\author{
D. Behera ${ }^{1}$, D. Mohanty ${ }^{1}$, D. P. Ghosh ${ }^{2}$, S. K. Saha ${ }^{1}$, R. Raj ${ }^{2}$ \\ ${ }^{1}$ Department of Mechanical Engineering, Indian Institute of Technology Bombay, India \\ dipankar1993@gmail.com; mohantydiptimoy@gmail.com; sandip.saha@iitb.ac.in \\ ${ }^{2}$ Department of Mechanical Engineering, Indian Institute of Technology Patna, India \\ durga.pme15@iitp.ac.in; rraj@iitp.ac.in
}

\begin{abstract}
In this paper, the thermal performance of nanostructured ( $\mathrm{CuO}$ nanostructures) copper multiple parallel microchannels for single-phase flow is studied. The test section consists of 6 parallel channels and each channel is $350 \mu \mathrm{m}$ wide and $605 \mu \mathrm{m}$ deep with an aspect ratio of 1.729. Microchannels are covered on the top surface with an acrylic sheet. A cartridge heater is inserted at the bottom of the microchannels for supplying the desired heat flux and the position of the heater is determined numerically. Deionized water (DI) is used as the working fluid in the experiment. Single-phase pressure drop and heat transfer coefficient in multiple nanostructured microchannels are measured. A maximum enhancement of $\sim 21 \%$ in Nusselt number is reported without any observable increase in pressure drop upon the incorporation of nanostructured in microchannels. The current study could provide a suitable low-cost framework for investigating the potential of nanostructures in further enhancement of single phase heat transfer coefficients in microchannel geometry.
\end{abstract}

Keywords: Microchannel, Copper, Nanostructured, Single Phase, Heat Transfer Coefficient.

\section{Introduction}

In recent years, microchannels have been studied extensively due to the rapid growth of applications requiring transfer of high heat fluxes [1]. Applications of microchannels range from compact heat exchangers employed in process and refrigeration industries to small scale thermal management devices for the cooling of microelectronic components such as computer processors as shown by Naphon et al. [2]. The advantages of these microscale devices, in addition to compactness, include reduced material requirement, low weight, smaller amount of coolant and high overall system efficiency. Microscale devices pave path for resource conservation and environmental protection.

Scaling down of the heat transfer results obtained from conventional sized channels to micro regime is widely debated due to contradictory results in the published literature. Entrance effects due to hydrodynamic and thermal development are very effective in short microchannels and significantly affect the pressure drop and heat transfer coefficient values. Webb [3] stated that for short channels, the portion of pressure drop due to the entrance and exit losses may be as high as $30 \%$ of the total pressure drop in the device. Ali et al. [4] experimentally investigated the single phase heat transfer and pressure drop in the rectangular microchannel in which the surface was coated with copper nanowires by electrochemical synthesis technique. The experimental results indicated an enhancement in Nusselt number $(\mathrm{Nu})$ at all Reynolds number $(R e)$ with a maximum enhancement of $24 \%$ at $R e=106$. Manay et al. [5] numerically evaluated pressure drop and laminar convection heat transfer characteristics of nanofluids in a square duct microchannel. Heat transfer increased with increasing $R e$ as well as particle volume concentration. At the same concentration and $R e$, heat transfer with $\mathrm{CuO}$-water nanofluid was found to be higher than that of $\mathrm{Al}_{2} \mathrm{O}_{3}$-water nanofluids. Lee and Mudawar [6] investigated the effectiveness of $\mathrm{Al}_{2} \mathrm{O}_{3}$-water nanofluids for single phase heat transfer in the microchannels. They reported higher heat transfer coefficient in entrance region in comparison to the heat transfer coefficient in the developed region.

In this work, the aim is to improve the single-phase heat transfer by deploying short microchannels such that the flow remains in the developing regime. Moreover, the role of nanostructures on heat transfer is also investigated. We show around $21 \%$ increase in heat transfer coefficients without any appreciable pressure drop penalty due to the incorporation of nanostructures. 


\section{Experimental Setup}

A schematic of the experimental setup is shown in figure 1. Deionized water (DI) water is used as the working fluid, which is drawn from the water reservoir and degassed unit. DI water is pumped using peristaltic pump (Make: Cole Parmer, Model: Master Flex L/S 2) to the test section through an accumulator. Accumulator is used for damping the flow fluctuations caused by the pump. A differential pressure transducer (Make: Omega, Model: PXM459-350DWUI) is connected across the test section to measure the pressure drop.

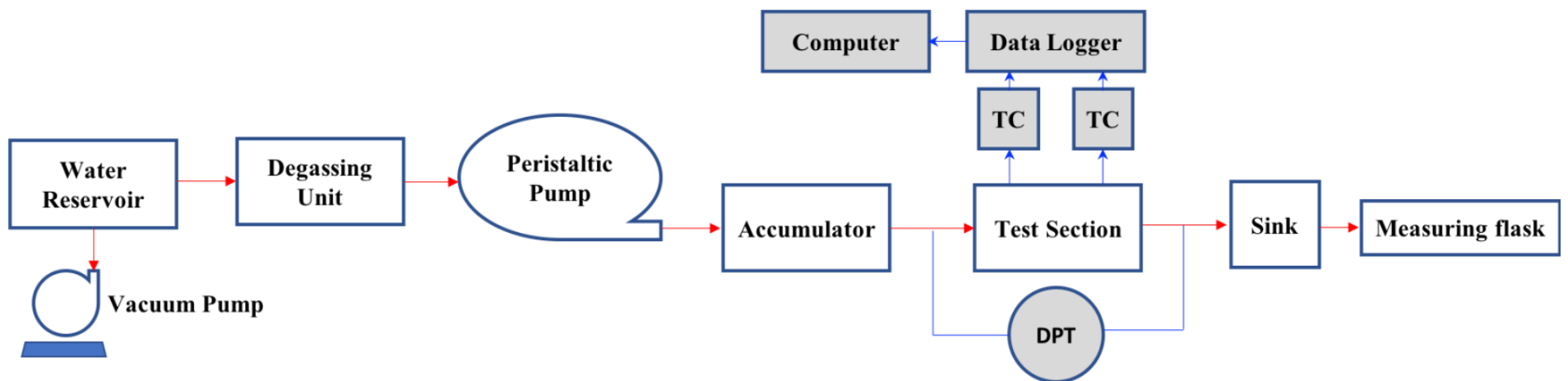

Fig. 1: Schematic diagram of the experimental setup.

Test section consists of six channels where each channel dimension is $350 \mu \mathrm{m}$ (width) $\times 605 \mu \mathrm{m}$ (depth) $\times 11 \mathrm{~mm}$ (length) as shown in figure 2(a). Two such test sections are manufactured by CNC micro-milling. The first test section contains plain/smooth channels while $\mathrm{CuO}$ nanostructures are grown by chemical oxidation process on the walls (two side walls and one bottom wall) of the second microchannel.

The test section assembly is shown in figure 2(b). Heat input to the microchannel is provided by cartridge heater inserted in a $6.8 \mathrm{~mm}$ diameter hole located vertically below the microchannel at a distance of $5 \mathrm{~mm}$ from the top surface of copper block. A DC electrical source (Make: Keithely, Model: 2200-60-2) is used to supply power to the cartridge. Four holes, 1 $\mathrm{mm}$ diameter $\times 14 \mathrm{~mm}$ deep, are drilled in the side of the copper test section, $1.5 \mathrm{~mm}$ below the top surface, to accommodate thermocouples for measuring the temperature distribution along the microchannel as shown in figure 3. A transparent acrylic sheet is bolted on the top of the test section and sealed with an O-ring. Holes are drilled on the acrylic sheet for (i) inlet and outlet of DI water, (ii) two thermocouples located at each inlet and outlet. The mass flow rate is measured using a measuring flask and stopwatch. Copper block, inlet and outlet temperatures are measured with $0.2 \mathrm{~mm}$ diameter T-type thermocouples.

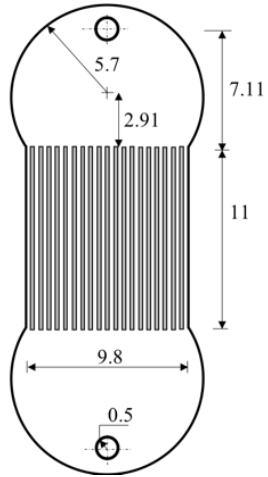

(a)

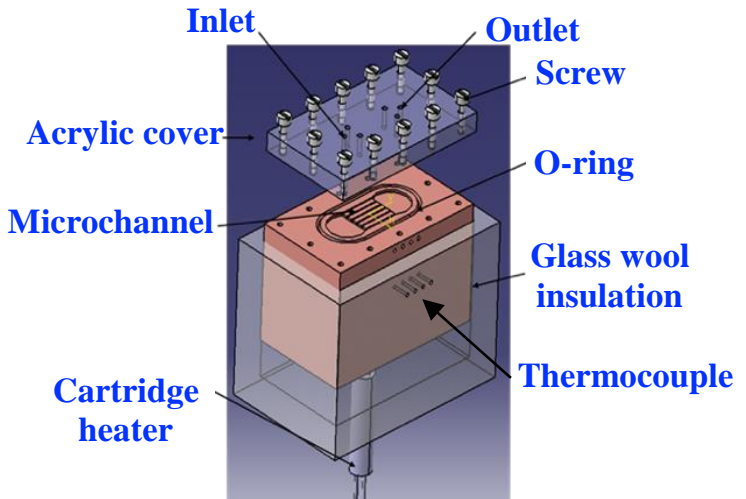

(b)

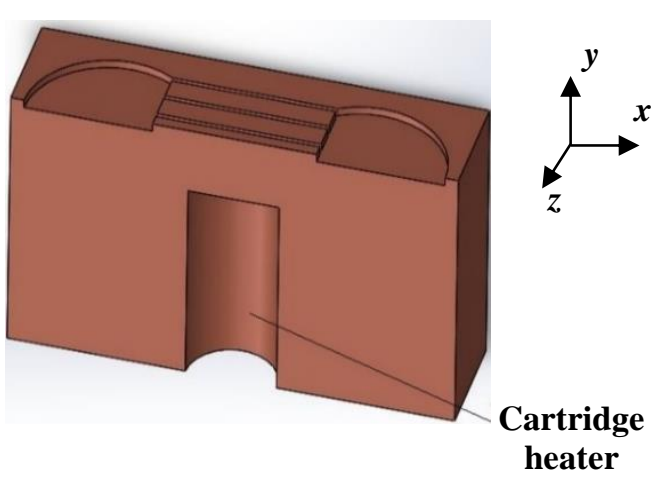

Fig. 2: (a) Microchannel design, (b) Dropdown figure of the test section, (c) Numerical domain (all dimensions are in $\mathrm{mm}$ ).

\subsection{Nanostructure Fabrication Method}

Nanostructures are grown on the walls of the microchannel to enhance heat transfer in microchannel. The steps for fabrication according to Miljkovic et al. [7] are given as, 
(i) The cleaning of laboratory glassware is performed in surfactant, Isopropyl alcohol (IPA, purity 99\%, CAS number 67-63-0, Qualigens Fine Chemicals) and acetone (purity 99\%, CAS number 67-64-1, Fisher Scientific).

(ii) Copper substrate is then cleaned for $10 \mathrm{~min}$ in ultrasonic bath with acetone and further rinsing in Ethanol, IPA and DI water.

(iii) Masking is performed in those areas to prevent growing of nanostructures.

(iv) It is dipped in hydrochloric acid (37\% pure, CAS number 7647-01-0, Fisher Scientific) for 10 min, which removes the native oxide coatings from the substrate.

(v) $\quad \mathrm{NaClO}_{2}$ (purity 80\%, CAS number 7758-19-2, Sigma Aldrich), NaOH (CAS number 1310-73-2, Central Drug House), and $\mathrm{Na}_{3} \mathrm{PO}_{4} .12 \mathrm{H}_{2} \mathrm{O}$ (purity 97.5\%, CAS number 10101-89-0, E. Merck "India" Limited) in the ratio 3.75:5:10 by weight in $100 \mathrm{ml}$ DI water.

(vi) At the same time DI water is heated in the magnetic stirrer with hot plate and the above chemicals are put when the temperature reaches $97^{\circ} \mathrm{C}$.

(vii) Finally, the copper substrate is dipped in the solution for $10 \mathrm{~min}$ and there after it is ultrasonicated in DI water followed by acetone for $10 \mathrm{~min}$.

SEM images of $\mathrm{CuO}$ nanostructures are shown in figure 3.
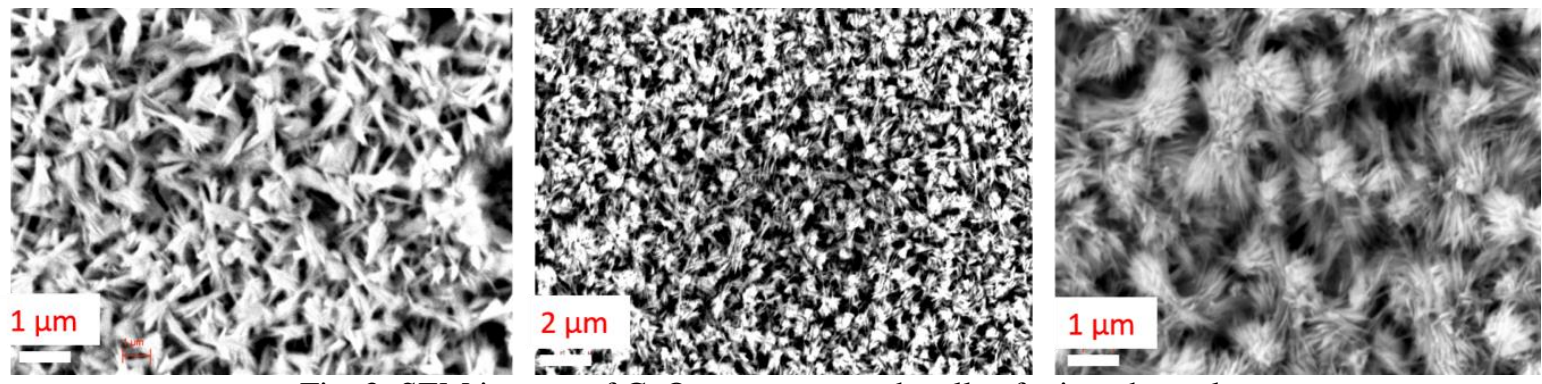

Fig. 3: SEM images of $\mathrm{CuO}$ nanostructured walls of microchannel.

\subsection{Pressure Drop and Nusselt Number}

(a) Pressure drop

There are three main components that contribute to the overall pressure drop. The inlet and exit losses need to be quantified for the microchannel. The hydrodynamic developing length needs to be carefully evaluated. Finally, the remaining length will have the fully developed frictional loss. Other different components that accounts for pressure drop are connector losses, $90^{\circ}$ bend losses, collector losses. Hence, the total measured pressure drop [8] during the experiment, $\Delta P_{\text {meas }}$ can be expressed as,

$$
\Delta P_{\text {meas }}=\Delta P_{c}+\Delta P_{\text {in }}+\Delta P_{e x}+\Delta P_{D}+\Delta P_{F D}+2 \Delta P_{b}
$$

where $\Delta P_{c}$ is the pressure loss due to the flow in the connecting tubes, $\Delta P_{i n}$ and $\Delta P_{e x}$ are the inlet and exit losses, $\Delta P_{D}$ is the developing region loss, $\Delta P_{F D}$ is the pressure drop in the fully developed region, $\Delta P_{b}$ is the pressure drop due to $90^{\circ}$ bends.

Connecting Tube Pressure Loss $\left(\Delta \mathrm{P}_{c}\right)$ : Connecting tube pressure drop accounts for the losses due to all fittings and the capillary tube from the pressure transducer to the microchannel inlet. Losses are measured directly at each flow rate when there is no microchannel at the end of the tubing. The measurements are carefully conducted with the conditions identical to the case when a microchannel is attached to the end of the connecting tube to avoid the effects of hydrostatic pressure.

Minor Losses $\left(\Delta \mathrm{P}_{\min }\right)$ : Other pressure losses associated with the measured pressure drop are inlet, exit, and $90^{\circ}$ bend losses. These losses are usually obtained from the traditional relationships used in macroscale [9-11]. Phillips [10] showed that the minor pressure losses can be obtained from,

$$
\Delta P_{\text {min }}=\Delta P_{\text {in }}+\Delta P_{e x}+\Delta P_{b}=\frac{\rho Q^{2}}{2 A}\left[K_{c}+K_{e}+2 K_{b}\left(\frac{A}{A_{t}}\right)^{2}\right]
$$


where $A$ and $A_{t}$ are the channel and connecting tube cross-sectional areas, respectively. $K_{b}$ is the loss coefficient for the bend, and $K_{c}$ and $K_{e}$ represent the contraction and expansion loss coefficients due to area changes in the flow. $K_{b}$ to be approximately 1.2 for a $90^{\circ}$ bend from Phillips [10].

Developing flow Pressure Loss $\left(\Delta \mathrm{P}_{\mathrm{D}}\right)$ : The non-dimensionless flow distance is given by,

$$
x^{+}=\frac{x}{D_{h} \cdot R e}
$$

where $x^{+}$is the non-dimensional flow distance and $x$ is the axial flow direction location. It is commonly accepted that for a value of $x^{+}=0.05$, the flow can be considered fully developed. When considering the developing flows, the pressure drop is now related to an apparent friction factor and is given as [12],

$$
\Delta P_{D}=\frac{2\left(f_{a p p} R e\right) \mu \bar{V} L_{d}}{D_{h}{ }^{2}}
$$

where $f_{a p p}$ is the apparent friction factor from Phillip [10] which is taken as $21.8, \mu$ is the viscosity, and $L_{d}$ is developing length. Considering developed flow, pressure drop is given by,

$$
\Delta P_{F D}=\frac{2(f R e) \mu \bar{V}\left(L-L_{d}\right)}{D_{h}{ }^{2}}
$$

whereas, $L$ is length of the microchannel and $f R e$ is given by [13],

$$
f R e=24\left(1-1.355 \alpha+1.9467 \alpha^{2}-1.7012 \alpha^{3}+0.9564 \alpha^{4}-0.2537 \alpha^{5}\right)
$$

The average Nusselt number in the microchannel is calculated in the following manner. The total input power is either dissipated as loss from the external surface of the microchannel and the fittings or result in the increase in the internal energy of the water flowing out to the reservoir. The second components (of interest to us in this work) can be quantified by measuring the flow rate and the temperature difference between the inlet and outlet temperature of the water. Therefore, the overall loss (W) can be written as,

$$
Q_{\text {loss }}=P-q_{\text {rem }}
$$

where $P$ is power supplied by heater in $\mathrm{W}$. The heat loss from the external surfaces is obtained by standard correlations reported in literature. The Nusselt number correlation for natural convection from a heated vertical plate is given by Kays et al. [14] as,

$$
N u_{\mathcal{L}}=0.68+0.67 R a_{\mathcal{L}}^{1 / 4}\left[1+\left(\frac{0.492}{P r}\right)^{\frac{9}{16}}\right]^{-\frac{4}{9}} \quad \text { for } \quad G r_{\mathcal{L}}<10^{9}
$$

The correlation for the top surface is given by,

$$
N u_{\mathcal{L}}=0.54 R a_{\mathcal{L}}^{1 / 4} \quad \text { for } 10^{4} \leq R a_{\mathcal{L}} \leq 10^{7}
$$


The heat removed by water can be obtained as,

$$
q_{\text {rem }}=\dot{m} c_{p f}\left(T_{\text {out }}-T_{\text {in }}\right)
$$

The average heat flux at the heated walls (bottom wall +2 sidewalls) of the channel is given by,

$$
q^{\prime \prime}=\frac{q_{r e m}}{A}
$$

where $A=(2 H+W) L, H=$ height of microchannel, $W=$ width of microchannel, $L=$ length of the microchannel. Hence, the average heat transfer coefficient is calculated as [15],

$$
\bar{h}=\frac{q^{\prime \prime}}{\Delta T_{l m}}
$$

and $\Delta T_{l m}$ is the logarithmic-mean temperature difference, which is defined as [15],

$$
\Delta T_{l m}=\frac{\left(T_{w}-T_{\text {in }}\right)-\left(T_{w}-T_{\text {out }}\right)}{\ln \frac{\left(T_{w}-T_{\text {in }}\right)}{\left(T_{w}-T_{\text {out }}\right)}}
$$

Therefore, average Nusselt number is calculated as,

$$
\overline{N u}=\frac{\bar{h} D_{h}}{k_{f}}
$$

Nusselt number for developing laminar flow is given by the correlation from Bejan [16],

$$
\overline{N u}=C\left(\frac{L / D_{h}}{R e P r}\right)^{-1 / 2}
$$

where $C$ is a constant which needs to be determined experimentally.

\subsection{Uncertainty Analysis}

The uncertainty analysis is carried out to estimate the uncertainty in the measured results due to uncertainties present in the primary measurements. A set of measurements is made and the uncertainty in each measurement is expressed. Let $R$ be a given function of the independent variables $x_{1}, x_{2}, x_{3} \ldots x_{n}$. Thus,

$$
R=R\left(x_{1}, x_{2}, x_{3} \ldots x_{n}\right)
$$

Let $w_{R}$ be the uncertainty in the result and $w_{1}, w_{2}, w_{3} \ldots w_{n}$ be the uncertainties in the independent variables. The uncertainty in the result is given as,

$$
\pm w_{R}=\left[\left(\frac{\partial R}{\partial x_{1}} w_{1}\right)^{2}+\left(\frac{\partial R}{\partial x_{2}} w_{2}\right)^{2}+\cdots+\left(\frac{\partial R}{\partial x_{n}} w_{n}\right)^{2}\right]^{\frac{1}{2}}
$$


Using this approach, the uncertainty in different variables is calculated and listed in Table 1.

Table 1: Uncertainty associated with different parameters.

\begin{tabular}{|c|c|}
\hline Parameters & Uncertainty \\
\hline Flow rate $(\mathrm{ml} / \mathrm{min})$ & \pm 0.37 \\
\hline Voltage supplied to heater $(\mathrm{V})$ & $\pm 0.1 \%$ \\
\hline Current to the heater $(\mathrm{A})$ & $\pm 0.1 \%$ \\
\hline Temperature $\left({ }^{\circ} \mathrm{C}\right)$ & \pm 0.2 \\
\hline Absolute inlet pressure $(\mathrm{mbar})$ & $\pm 0.25 \%$ \\
\hline Pressure drop $(\mathrm{mbar})$ & $\pm 0.25 \%$ \\
\hline Nusselt number & \pm 0.035 \\
\hline Heat transfer coefficient $\left(\mathrm{W} / \mathrm{m}^{2} \mathrm{~K}\right)$ & $\pm 6.5 \%$ \\
\hline
\end{tabular}

\section{Numerical Modelling}

To find the optimum location of the cartridge heater inside the copper block, the following assumptions are made for the flow and heat transfer inside the microchannels, viz. (i) steady state analysis, (ii) Newtonian, incompressible and laminar flow, (iii) thermophysical properties of materials are constant, (iv) negligible radiative and natural convective dissipation, and (v) negligible axial conduction and viscous dissipation. The mathematical model based on the aforementioned assumptions for analysing three-dimensional conjugate heat transfer in microchannel is given by the following equations.

For fluid:

$$
\begin{gathered}
\frac{\partial u_{i}}{\partial x_{i}}=0 \\
\rho u_{i} \frac{\partial u_{j}}{\partial x_{i}}=-\frac{\partial P}{\partial x_{i}}+\frac{\partial}{\partial x_{j}}\left[\mu \frac{\partial u_{i}}{\partial x_{j}}\right] \\
\rho c_{p f}\left(u_{i} \frac{\partial T_{f}}{\partial x_{i}}\right)=\frac{\partial}{\partial x_{i}}\left[k_{f} \frac{\partial T_{f}}{\partial x_{i}}\right]
\end{gathered}
$$

For solid:

$$
\frac{\partial}{\partial x_{i}}\left[k_{s} \frac{\partial T_{s}}{\partial x_{i}}\right]=0
$$

The cross-section of the microchannel having six channels (width $=300 \mu \mathrm{m}$, length $=11 \mathrm{~mm}$ and depth $=600 \mu \mathrm{m}$ each), along with the cartridge heater, which is considered as the numerical domain, is shown in figure 2(c).

Boundary and interface conditions

The fluid velocities at the wall boundaries are zero and the mass flow inlet boundary condition is specified at the inlet of the plenum and the pressure outlet boundary condition is given at the outlet of the plenum. The walls of the copper block are considered to be insulated. The entire microchannel is divided into half which is considered as the numerical domain in this analysis (figure 2(c)), hence symmetry boundary condition is used at the mid-plane. The mesh size used is $10 \mu \mathrm{m}$ in the microchannel and $0.5 \mathrm{~mm}$ grid size is adopted in the heater and the heater block after grid independence study.

At the interface of solid and liquid, the following conditions are applied, 


$$
\begin{aligned}
-\left.k_{f} \frac{d T_{f}}{d n}\right|_{\text {interface }} & =-\left.k_{s} \frac{d T_{s}}{d n}\right|_{\text {interface }} \\
\left.T_{f}\right|_{\text {interface }} & =\left.T_{s}\right|_{\text {interface }}
\end{aligned}
$$

The continuity momentum and energy equations are solved by SIMPLE algorithm in a finite volume based computational fluid dynamics (CFD) software, ANSYS FLUENT 14. The velocity of water at the inlet is varied from 0.00025 to $0.0001 \mathrm{~kg} / \mathrm{s}$. The temperature at the inlet is kept at $300 \mathrm{~K}$. The pressure is discretized using the standard scheme and the coefficients in momentum and energy equations are discretized using QUICK scheme. The SIMPLE algorithm is employed for velocity- pressure coupling in the multiple grid solution procedure.

\section{Results and Discussions}

\subsection{Location of Heater}

Figure 4 shows the numerically predicted difference $(\Delta T)$ between the maximum and minimum temperature at the bottom surface of the microchannel with distances $\left(z_{c}\right)$ from the top surface of the cartridge heater to the microchannel top surface for three different flow rates viz. $0.00025 \mathrm{~kg} / \mathrm{s}, 0.0005 \mathrm{~kg} / \mathrm{s}$, and $0.001 \mathrm{~kg} / \mathrm{s}$ for $50 \mathrm{~W}$ of heat input. The relationship between $\Delta T$ and $z_{c}$ provides the uniformity with which heat is supplied to the bottom of microchannel. It can be observed from the figure that $\Delta T$ are higher for low inlet flow rates and it decreases as the distance of the cartridge heater from the top of the microchannel is reduced. However, there is an interesting feature, which must be noted. $\Delta T$ decreases as the distance increases from 1 to $1.5 \mathrm{~mm}$. This particular observation can be made for different flow rates. The temperature difference continuously decreases with an increase in the distance from the top of the cartridge heater to the top of the block after 1.5 $\mathrm{mm}$. However, the change in $\Delta T$ is small after the distance of $5 \mathrm{~mm}$. Hence, in the experimental setup, the cartridge heater is located at $5 \mathrm{~mm}$ from the top surface of the microchannel.

\subsection{Pressure Drop and Nusselt Number}

Experiments are performed for different flow rates ranging from 3.41 to $25.86 \mathrm{ml} / \mathrm{min}$, and the corresponding range of Reynolds number is 73.8 to 559.74. Analytically, the pressure drop is obtained from Steinke et al. [17] and Mirmanto et al. [15] by taking into consideration of inlet and exit losses, pressure drop due to connecting tubes and connectors, $90^{\circ}$ bend loss and reservoir losses. In experiments, the pressure drop is measured by a differential pressure transducer and is shown in figure 5(a). It can be observed from the figure that there exists good agreement between analytical pressure drop and the experimentally measured pressure drop for plain microchannel. It is found that the pressure drop in nanostructured microchannel is slightly higher in comparison with that in plain copper microchannel.

Figure 5(b) shows the variation of the average Nusselt number with the Reynolds number. By fitting equation (15) the results of $15 \mathrm{~W}$, the value of $C$ is found to be equal to 1.55 , which shows good agreement with results of $20 \mathrm{~W}$ and $25 \mathrm{~W}$. 


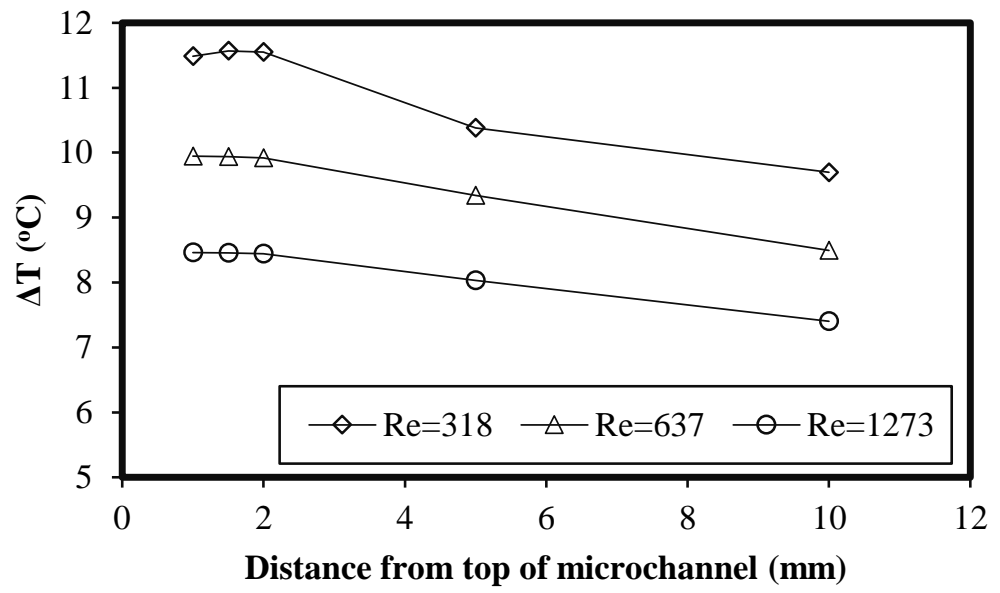

Fig. 4: Difference in maximum and minimum temperature at the bottom surface of the microchannel with distances from the top of the cartridge heater to the microchannel top surface for three different flow rates for $50 \mathrm{~W}$ of heat input.

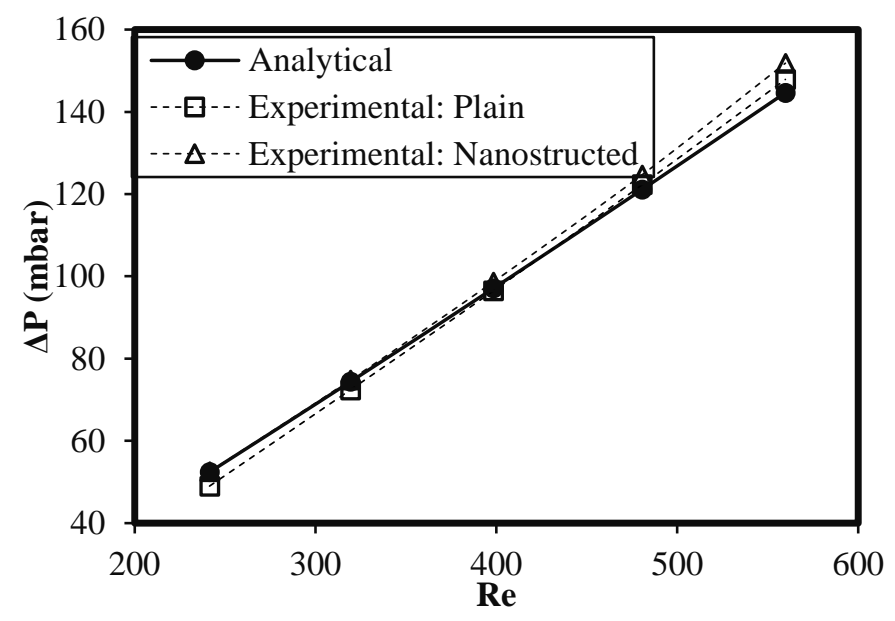

(a)

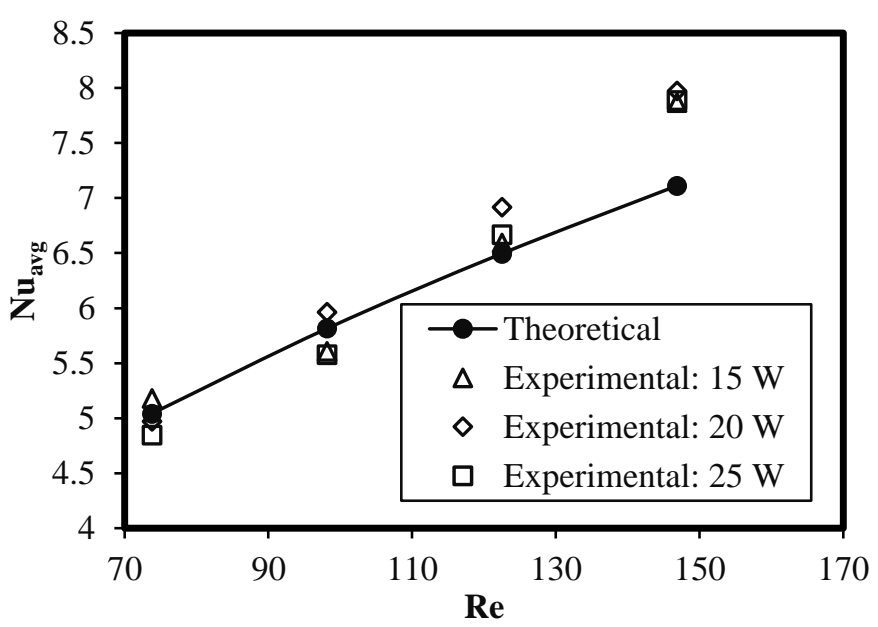

(b)

Fig. 5: Comparison of theoretical and experimental (a) Pressure drop, (b) Average $N u$ for different $R e$.

\subsection{Heat Transfer Coefficient}

The present work deals with single phase flow in plain and nanostructured microchannels. The thermocouples are inserted inside the copper block at the positions shown in figure 2(b). Figure 6 shows the average heat transfer coefficient for plain and nanostructure microchannels for 15 and $25 \mathrm{~W}$ for different flow rates. It can be inferred from the figure that there is an increment in the heat transfer coefficient values in the nanostructured microchannels compared to the microchannels without nanostructures. The increase in the $h$ can be attributed to the formation of the grass like nanostructures, which provide greater surface area for heat transfer. The average percentage increase is $\sim 21 \%$ for $15 \mathrm{~W}$, whereas, it is $\sim 13 \%$ for $25 \mathrm{~W}$ heat input. This can be attributed to increase in heat losses at high heat input. 


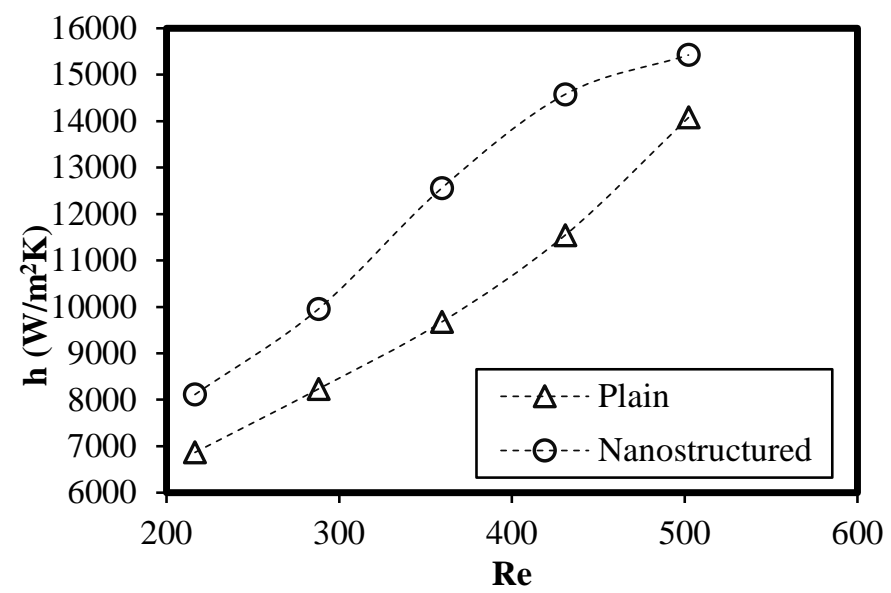

(a)

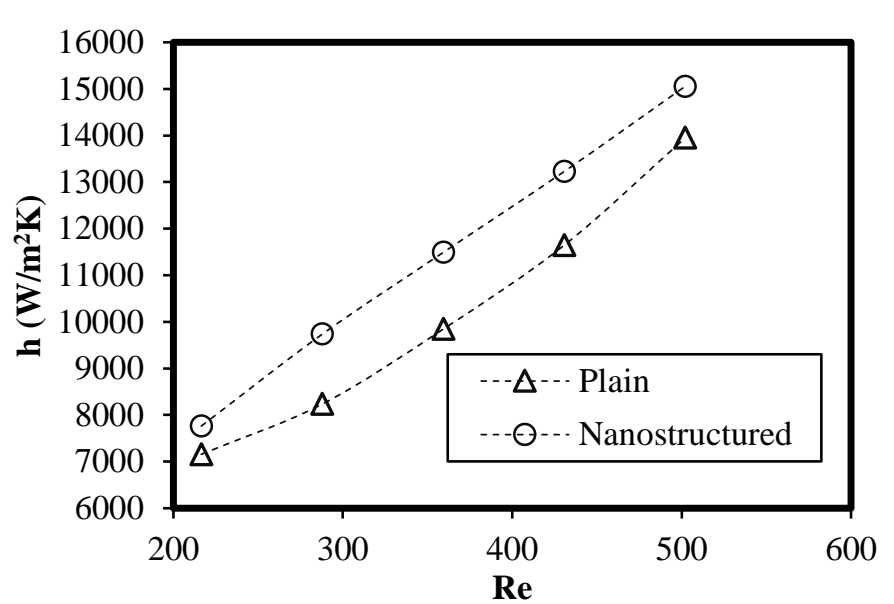

(b)

Fig. 6: Variation of average heat transfer coefficient (h) with flow rate for (a) $15 \mathrm{~W}$ and (b) $25 \mathrm{~W}$.

\section{Conclusion}

The experiment is performed on plain and nanostructured copper microchannels. It is found that there is a thermal enhancement of $21 \%$ in the Nusselt number without any observable increase in pressure drop after the incorporation of $\mathrm{CuO}$ nanostructures on the walls of the microchannels. However, the pressure drop in nanostructured microchannel is found to be slightly higher than that in plain copper microchannel. With the increase in the heat flux at a constant flow rate, the pressure drop decreases. It is clearly deduced that there is an enhancement of heat transfer using nanostructure technique. Hence, this enhancement technique can be effectively used for various purposes at low cost budget.

\section{Nomenclature}

A Area $\left(\mathrm{m}^{2}\right)$

C Constant

$c_{p} \quad$ Specific heat $(\mathrm{J} / \mathrm{kg} . \mathrm{K})$

$D_{h} \quad$ Hydraulic diameter (m)

$f \quad$ Friction factor

$\mathrm{Gr}$ Grashof number

$\bar{h} \quad$ Average heat transfer coefficient $\left(\mathrm{W} / \mathrm{m}^{2} . \mathrm{K}\right)$

$K \quad$ Loss coefficient

$k \quad$ Thermal conductivity (W/m.K)

$L \quad$ Length (m)

$\mathcal{L} \quad$ Characteristics length $(\mathrm{m})$

$L_{d} \quad$ Developing length (m)

$\dot{m} \quad$ Mass flow rate $(\mathrm{kg} / \mathrm{s})$

$\mathrm{Nu}$ Nusselt Number

$n \quad$ Vector normal to the surface

$R a \quad$ Rayleigh number

\section{Greek symbols}

$$
\begin{array}{ll}
\alpha & \text { Aspect ratio } \\
\rho & \text { Density }\left(\mathrm{kg} / \mathrm{m}^{3}\right)
\end{array}
$$

\section{Subscript}

$\begin{array}{ll}\text { app } & \text { Apparent } \\ b & \text { Bends } \\ c & \text { Connecting }\end{array}$

$\begin{array}{ll}R e & \text { Reynolds number } \\ P & \text { Power }(\mathrm{W}) \\ P r & \text { Prandtl number } \\ \Delta P & \text { Pressure drop (mbar) } \\ Q & \text { Flow rate }(\mathrm{ml} / \mathrm{min}) \\ Q_{\text {loss }} & \text { Overall heat loss }(\mathrm{W}) \\ q^{\prime} & \text { Heat flux }\left(\mathrm{W} / \mathrm{m}^{2}\right) \\ q & \text { Heat transfer rate }(\mathrm{W}) \\ T & \text { Temperature }\left({ }^{\circ} \mathrm{C}\right) \\ \Delta T & \text { Temperature difference }\left({ }^{\circ} \mathrm{C}\right) \\ u_{i} & \text { Velocity components in } x, y, z \text { directions } \\ \bar{V} & \text { Average velocity }(\mathrm{m} / \mathrm{s}) \\ W & \text { Width (m) } \\ x & \text { Axial flow direction location }(\mathrm{m}) \\ x^{+} & \text {Non-dimensional flow distance } \\ x, y, z & \text { Coordinate axes } \\ \mu & \text { Viscosity (Pa.s) } \\ \mu & \\ & \\ \text { in } & \text { Inlet } \\ \text { meas } & \text { Measured } \\ \text { min } & \text { Minor }\end{array}$




$\begin{array}{llll}D & \text { Developing } & \text { out } & \text { Outlet } \\ e x & \text { Exit } & \text { rem } & \text { Removal } \\ f & \text { Fluid } & s & \text { Solid } \\ F D & \text { Fully developed } & w & \text { Wall }\end{array}$

\section{Acknowledgement}

The authors would like acknowledge the funding support by Department of Science and Technology, India (Project No. SB/S3/MMER/0023/2014). The authors would like to acknowledge the support from the Indian Institute of Technology Bombay and the Indian Institute of Technology Patna. Mr. Dipankar Behera, Mr. Diptimoy Mohanty and Mr. Durga Prasad Ghosh have contributed equally in this work.

\section{References}

[1] I. Mudawar, "Assessment of high-heat-flux thermal management schemes," IEEE Transactions: Components and Packaging Technologies, vol. 24, no. 2, pp. 122-140, 2001.

[2] P. Naphon and S. Wiriyasart, "Liquid cooling in the mini-rectangular fin heat sink with and without thermoelectric for CPU," International Communications in Heat and Mass Transfer, vol. 36, pp. 166-171, 2009.

[3] R. L. Webb, "Entrance and exit losses for developing flow in parallel plate channels," Heat Transfer Engineering, vol. 27, no. 10, pp. 30-35, 2006.

[4] Y. M. Ali, F. Yang, R. Fang, L. Chen and J. Khan, "Thermohydraulic characteristics of a single-phase microtube heat sink coated with copper nanowires," Frontiers in Heat Mass Transfer, vol. 2, pp. 451-534, 2011.

[5] E. Manay, B. Sahin, M. Yilmaz and K. Gelis, "Thermal Performance Analysis of Nanofluids in Microchannel Heat Sinks," International Journal of Mechanical and Mechatronics Engineering, World Academy of Science, Engineering and Technology, vol. 6, no. 7, pp.1130-1135, 2012.

[6] J. Lee and I. Mudawar, "Assessment of the effectiveness of nanofluids for single-phase and two-phase heat transfer in micro-channels," International Journal of Heat and Mass Transfer, vol. 50, no. 3, pp. 452-463, 2007.

[7] N. Miljkovic, D. J. Preston, R. Enright and E. N. Wang, "Dynamics of coalescence-induced jumping water droplets," in: arXiv.org, Cornell University Library, 2013, p. 4.

[8] M. Akbari, D. Sinton and M. Bahrami, "Pressure drop in rectangular microchannels as compared with theory based on arbitrary cross section," Journal of Fluids Engineering, vol. 131, no. 4, pp. 041202-1-041202-8, 2009.

[9] J. Judy, D. Maynes and B. W. Webb, "Characterization of frictional pressure drop for liquid flows through microchannels," International Journal of Heat and Mass Transfer, vol. 45, no. 17, pp. 3477-3489, 2002.

[10] R. J. Phillips, "Microchannel Heat Sinks, Advances in Thermal Modeling of Electronic Components and Systems," Hemisphere, New York, Chapter 3, 1990.

[11] S. Kandlikar, S. Garimella, D. Li, S. Colin and M.R. King, "Heat transfer and fluid flow in minichannels and microchannels," Elsevier, 2005.

[12] S. Kakaç, R. K. Shah, and W. Aung, "Handbook of Single-Phase Convective Heat Transfer," Wiley-Interscience, 1987.

[13] R. K. Shah and A. L. London, "Laminar Flow Forced Convection in Ducts," Supplement 1 to Advances in Heat Transfer, Academic, New York, 1978.

[14] W. M. Kays and A. L. London, "Compact Heat Exchangers," McGraw-Hill, New York, 1984.

[15] Mirmanto, D. B. R. Kenning, J. S. Lewis and T. G. Karayiannis, "Pressure drop and heat transfer characteristics for single phase developing flow of water in rectangular microchannels," Journal of Physics: Conference Series, vol. 395, 012085 , p. 13, 2012.

[16] A. Bejan, "Convection Heat Transfer," 3rd ed, Hoboken, NJ: John Wiley and Sons, 2004.

[17] M. E. Steinke and S. G. Kandlikar, "Single-phase liquid friction factors in microchannels," International Journal of Thermal Sciences, vol. 45, pp. 1073-1083, 2006. 